\title{
LOS ENFOQUES DE LA GEOGRAFÍA EN SU EVOLUCIÓN COMO CIENCIA
}

\author{
Dr. Dante Edin Cuadra \\ Profesor e investigador del Dpto. de Geografía \\ Facultad de Humanidades. Universidad Nacional del Nordeste \\ dantecuadra@yahoo.com
}

\section{Resumen}

La geografía como conocimiento tiene una larga historia, pero recién logró afirmarse como disciplina científica a fines del siglo XIX, tras los valiosos aportes de Humboldt, Ritter, Richthofen y Ratzel y su inclusión inicial en las instituciones universitarias alemanas. A lo largo del tiempo, fueron numerosos los paradigmas que la influyeron $y$, en tal sentido, fue adoptando diferentes enfoques para abordar su objeto de estudio: el espacio geográfico. Estas perspectivas han mostrado un denominador común en la mayor parte del camino recorrido por la geografía: la coexistencia.

Algunos enfoques adquieren mayor relevancia que otros en determinados tramos de tiempo, pero todos siguen en carrera con sus diferentes y valiosas miradas que proyectan sobre la realidad. En pleno siglo $\mathrm{XXI}$, en universidades, centros de investigación y restantes instituciones científicas, se aprecian grupos de investigadores distribuidos en las más variadas corrientes geográficas, algunas tradicionales (como la general y sistemática, regional, ecológica humana, cultural) y, otras, con trayectorias más recientes, posteriores a la segunda guerra mundial (como sucede con los enfoques cuantitativo, sistémico, de la percepción y el comportamiento, radical, humanista, ambiental, automatizado y cultural posmoderno).

Palabras claves: Geografía; Enfoques; Ciencia; Paradigmas; Teorías; Evolución.

\section{APPROACHES OF GEOGRAPHY IN ITS EVOLUTION AS A SCIENCE}

\section{Summary}

Geography as knowledge has a long history, but only managed to establish itself as a scientific discipline in the late nineteenth century, after the valuable contributions of Humboldt, Ritter, Ratzel and Richthofen and its initial inclusion in the German universities. Throughout time, there were numerous paradigms that influenced it and, in that sense, it took different approaches to address its subject matter: the geographical space. These perspectives have shown a common denominator in most of the journey of geography: coexistence.

Some approaches become more relevant than others in certain stretches of time, but all of them are still in race with their different and valuable views on reality. Today, in the XXI century, in universities, research centers and other scientific institutions, we can find research groups distributed in the most varied range of geographical currents, some traditional (such as general and systematic, regional, human ecological, and cultural geography) and others, with more recent trajectories, subsequent to world War II (as happens with quantitative, systemic, perception and behavior, radical, humanist, environmental, automated and cultural postmodern approaches).

Key words: Geography; Approaches; Science; Paradigms; Theories; Evolution.

\section{Sumario del artículo}

Introducción.

Desarrollo:

-Los enfoques geográficos tradicionales.

-Los enfoques geográficos posteriores a la segunda guerra mundial.

-Distintas interpretaciones sobre la evolución de la geografía como ciencia.

-Paradigmas y enfoques.

A modo de síntesis: los aspectos más relevantes de cada enfoque geográfico.

Bibliografía consultada.

Publicado en formato digital: Dr. Dante Edin Cuadra. LOS ENFOQUES DE LA GEOGRAFíA EN SU EVOLUCIÓN COMO CIENCIA. Revista Geográfica Digital. IGUNNE. Facultad de Humanidades. UNNE. Año 11. No 21. Enero - Junio 2014. ISSN 1668-5180 Resistencia, Chaco.

En: http://hum.unne.edu.ar/revistas/geoweb/default.htm 
Revista Geográfica Digital. IGUNNE. Facultad de Humanidades. UNNE. Año 11. № 21.

Enero - Junio 2014. ISSN 1668-5180 Resistencia, Chaco

\section{Introducción}

Mucho se ha escrito en el amplio campo de la teoría y de la epistemología de la geografía acerca de cómo se entiende la evolución de la ciencia geográfica. Tradicionalmente se aceptó que el conocimiento registraba progresos o avances, es decir que -con el transcurso del tiempo- los conocimientos se añadían a los ya existentes (unos hacían de soportes o trampolín de los siguientes), en tanto otros perdían vigencia o se desactualizaban (concepción lineal o cronológica). Asimismo, en la medida en que las sociedades entraban en contacto o desarrollaban estrategias de comunicación, garantizaban la posibilidad de incorporación, intercambio y complementación de nuevos conocimientos, métodos, técnicas y prácticas.

El conocimiento geográfico es, sin dudas, tan antiguo como el hombre y, en distintos puntos de la Tierra, los saberes geográficos fueron parte indisoluble del desarrollo de las sociedades e, incluso, de la consolidación y expansión de los Estados y de los grandes imperios. No se pueden imaginar las dinastías chinas, la milenaria India, el antiquísimo Egipto, la Mesopotamia asiática, la civilización cretense, la expansión fenicia, la instalación hebrea en Palestina, la colosal organización del imperio griego con Alejandro Magno o el poderío del imperio romano, sin un gran cúmulo de conocimientos geográficos.

Existe consenso general en catalogar como la Edad Antigua de la geografía al período que se extendió entre los siglos VII a.C. y II d.C, justamente en la Antigua Grecia, donde filósofos y pensadores brindaron muchos conceptos y desarrollaron mediciones y cálculos que hasta entonces no eran conocidos, además de sostener la idea de la esfericidad de la Tierra. Grecia es reconocida como la cuna de la geografía, dado que fue allí donde este campo del saber se constituyó como descripción rigurosa a través de escuelas como la Jónica, Pitagórica, Metropolitana y Alejandrina y de los eximios pensadores, de la talla de Anaximandro, Pitágoras, Heródoto, Platón, Aristóteles, Eratóstenes, Estrabón, Plinio El Viejo y Claudio Ptolomeo, junto a muchos otros. De hecho, Aristóteles fue el primero en usar el término geografía y Estrabón en publicar una obra con ese nombre. (Daus, F., 1978)

El conocimiento como tal no tenía fronteras disciplinares, de modo que un pensador podía abocarse a la filosofía, astronomía, geografía, historia, cartografía, matemática, física y otros campos del saber.

Luego de algunas centurias de silencio, pasado el apogeo helénico, se ha identificado al Medioevo como una larga etapa (siglos $\mathrm{V}$ al $\mathrm{XV}$, desde la caída del imperio romano occidental en el año 476 hasta el derrumbe del imperio romano oriental en 1453 o el descubrimiento de América por Colón en 1492) durante la cual la geografía perdió, en el mundo europeo, precisión y credibilidad, convirtiéndose en un género literario en el que se entremezclaban descripciones de viajes con fantasías y leyendas, desatendiendo el rigor descriptivo y las exactitudes cartográficas alcanzadas por los griegos. Fue un período de proliferación artística en los ámbitos de la pintura, la escultura, la arquitectura, la música y la literatura. El peso de la iglesia católica papal reforzaba la concepción teocéntrica y la creencia de que la tierra era un disco en el centro del universo. Por cierto, la influencia romana, a pesar del poderío político y económico alcanzado, no tuvo una trascendencia parangonable con la de los griegos en el campo de la geografía, debido al pragmatismo de esta cultura: llevaron a cabo una geografía utilitaria (catastros, caminos, edificios, urbanización, acueductos, puentes) que les permitió una dominación del espacio, sin una preocupación profunda por los aspectos teóricos o filosóficos del saber geográfico.

En el mundo islámico, fuera del control eclesiástico papal, la geografía no pasó por un oscurantismo como el europeo, sino que brilló al traducirse obras de los griegos al árabe e innovarse con las descripciones de viajeros, investigadores y cartógrafos como Al Idrisi, Batuta y Jaldún.

La Edad Moderna, caracterizada por los grandes descubrimientos geográficos (los viajes de Colón, Vespucio, Magallanes, Elcano, entre muchos), los aportes cartográficos como los de Mercator y Ortelius y, más tarde, en el siglo XVII, la invalorable contribución de Varenio, en la que anticipó la existencia de una geografía general y una geografía especial, destacando la importancia de las relaciones en el espacio, a las que llamó "affectiones". El final de esta etapa, atribuido a la Revolución francesa de 1789, ya conocía las ideas del filósofo alemán Immanuel Kant, que tanta influencia tendrían en las ciencias de los siglos posteriores. En la edad moderna la geografía cobró esplendor en Europa Occidental (tanto la cartografía como la corografía), se recuperaron obras del pasado y se

Publicado en formato digital: Dr. Dante Edin Cuadra. LOS ENFOQUES DE LA GEOGRAFÍA EN SU EVOLUCIÓN COMO CIENCIA. Revista Geográfica Digital. IGUNNE. Facultad de Humanidades. UNNE. Año 11. No 21. Enero - Junio 2014. ISSN 1668-5180 Resistencia, Chaco.

En: http://hum.unne.edu.ar/revistas/geoweb/default.htm 
vivió una renovación con los sucesivos descubrimientos, produciéndose una secularización del conocimiento (antropocentrismo). Asimismo, tuvo lugar la reforma protestante, surgió la imprenta, se inició la sistematización científica y el pre-capitalismo, se produjeron grandes avances en materia de navegación, se desarrolló la industria, se desencadenaron revoluciones a nivel geográfico, étnico, social, económico, religioso, alimentario y científico y, en su tramo final, se independizó Estado Unidos.

La Edad Contemporánea se inició en 1789, en plena Ilustración (movimiento artístico, científico y cultural que se extendió desde fines del siglo XVII hasta fines del XVIII y, en algunos países, hasta principios del XIX) y fue la época en que llegaron a su fin las monarquías absolutistas. Los aportes, sobre todo de Humboldt (adscripto al movimiento cultural y político conocido como Romanticismo entre fines del siglo XVIII y primera mitad del XIX), Ritter y las posteriores contribuciones de Richthofen y Ratzel sirvieron de fundamento para cerrar el ciclo formativo de la geografía como ciencia, el cual se extendió desde fines del siglo XVIII hasta las postrimerías del siglo XIX, en un contexto de fuerte impulso de las Ciencias Naturales, de la doctrina determinista y del método inductivo. Pensadores como Kant y Hegel, la filosofía positivista comtiana y el evolucionismo darwiniano (como paradigmas) ejercían su influjo en el campo de las ciencias. Con posterioridad a 1880 la geografía logró definirse, previa crisis desatada después de las muertes de Humboldt y de Ritter (ocurridas en 1859), adquiriendo un gran desarrollo, rigor académico (en sus contenidos, métodos y principios), presencia institucional en todos los niveles educativos, fuerte gravitación de grandes referentes (Richthofen, Ratzel, Penk, Mackinder, los regionalistas: Vidal de la Blache y sus discípulos en Francia y Hettner en Alemania). También se desarrolló la concepción filosófica historicista (sintetizada por Dilthey), se postuló el posibilismo como doctrina (enunciada por Lucien Febvre a partir de las ideas anti-deterministas de Vidal de la Blache), proliferaron los centros de investigación, se habilitaron doctorados en diversas universidades, aumentaron inusitadamente las publicaciones en formatos de libros, atlas, revistas y se realizaron congresos de la disciplina, con la respectiva difusión de sus actas. (Estebanez, J., 1992)

La Edad Contemporánea representa un período de dos siglos en los que ha acaecido una multitud de sucesos: revolución industrial y tecnológica, fuerte urbanización, imposición del liberalismo económico, transiciones demográficas, desarrollo del comercio, emancipación de la mujer y expansión de los regímenes democráticos en gran parte del mundo, avances de los transportes y de las comunicaciones, mejoramiento de la salud y de la esperanza de vida, apertura de los mercados y fronteras, conformación de la Unión Europea, caída del $2^{\circ}$ mundo (comunismo), adquisición de mayores libertades en la circulación de las ideas y, hacia el tramo final del siglo XX, la organización global (sociedades en red).

No se debe ignorar que en el transcurso de la Edad Contemporánea también ocurrieron hechos no sólo indeseables, sino despreciables, como la colonización impulsada por los países hegemónicos, la eclosión de regímenes autoritarios, las guerras mundiales, las explosiones de bombas atómicas, el holocausto judío, el tráfico de armas y el narcotráfico, sólo por citar algunos.

La última etapa, aún indefinida, es conocida como la Posmodernidad y, si bien no existen consensos absolutos en cuanto a sus inicios, podría tomarse el año 1989 como tal, considerando un hecho épico a nivel mundial como ha sido la caída del muro de Berlín, un ícono de unidad entre mundos ideológicos antagónicos y divididos. Tampoco está muy claro si la Posmodernidad es una etapa diferente, una continuidad o una eclosión de lo moderno-contemporáneo (del capitalismo). En palabras de Harvey la posmodernidad representa "un campo minado de nociones en conflicto". (Harvey, D., 1998). El llamado "giro cultural" producido en los años '80, detectado y enunciado inicialmente por universidades europeas y norteamericanas, puso en evidencia una serie de cambios que le otorgaron centralidad al hombre, entre ellos: el rechazo a los dogmas, la aceptación de verdades provisorias, nuevas socialidades, temporalidades, simbolismos y discursos, además de la resignificación de conceptos, instituciones y espacios.

Publicado en formato digital: Dr. Dante Edin Cuadra. LOS ENFOQUES DE LA GEOGRAFÍA EN SU EVOLUCIÓN COMO CIENCIA. Revista Geográfica Digital. IGUNNE. Facultad de Humanidades. UNNE. Año 11. No 21. Enero - Junio 2014. ISSN 1668-5180 Resistencia, Chaco.

En: http://hum.unne.edu.ar/revistas/geoweb/default.htm 


\section{Desarrollo}

\section{Los enfoques geográficos tradicionales}

Al decir de Ostuni, los geógrafos son "...criaturas de su tiempo que reaccionan al clima intelectual, social y político de la época en que viven..." (Ostuni, J., 1992). En otras palabras, el surgimiento de enfoques o perspectivas geográficas responden a concepciones, teorías, doctrinas, filosofías o ideologías que -solas o agrupadas- hacen una erupción exitosa dentro de un contexto socio-cultural hasta su aceptación como "paradigma/s" por parte de un conjunto de campos disciplinares o la totalidad de ellos.

Hasta mediados del siglo XX los enfoques que asomaron en la escena geográfica, algunos con mayor presencia y perdurabilidad que otros, fueron los siguientes:

La geografía general y sistemática enciclopedista (su embrión se halla en la antigua geografía griega, mostró algunos chispazos en la Edad Media en el ámbito musulmán (Norte de África y Sur de Europa) y, posteriormente, en el siglo XVII en Europa, lo tuvo a Varenio como un verdadero visionario con su obra "Geografía General y Especial". Pero la geografía general recién inició su etapa constitutiva a fines del siglo XVIII, llegando al apogeo en la centuria siguiente con los valiosos aportes de Humboldt, Ritter, Ratzel y Richthofen y su posterior institucionalización como disciplina, manteniéndose en pie aún en nuestros días. Las ramas más cultivadas desde esta óptica son la geografía física y la biogeografía (entre ambas constituyen la Fisiografía), aunque algunas subramas de la geografía humana suelen abordarse con esta modalidad, por ejemplo, la geografía económica, la geografía urbana y la geografía agraria.

La geografía regional (especial o excepcional) tuvo sus gérmenes en la cultura griega (Heródoto) y greco-latina (Estrabón), asomó tímidamente con Varenio, pero recién iniciaría su carrera con vigor y perduración a partir de 1880 con Paul Vidal de la Blache (líder de la escuela francesa), logrando una fuerte presencia durante gran parte del siglo XX con los discípulos de aquél maestro, más los aportes de la escuela alemana liderada por Alfred Hettner y, más tarde, de la escuela norteamericana con Richard Hartshorne a la cabeza. Posteriormente perdió gran parte de su poderío a expensas del cuantitativismo, aunque mostró algunos indicios de recuperación en ciertos tramos de la segunda mitad del siglo XX e inicios del XXI.

La geografía anarquista, sobre todo en la segunda mitad del siglo XIX, de la mano de Pedro Kropotkin y Eliseo Réclus, no tuvo aceptación, ni cabida en los círculos académicos de gran parte de Europa, dado que sus ideas anticolonialistas, antinacionalistas y crítico-sociales eran consideradas antipáticas y marginales. Sin embargo, sus aportes (dejando de lado la marcada adhesión al positivismo que exhiben sus obras) implantaron los rudimentos para que en las últimas décadas del siglo XX estos temas fueran retomados y cobraran una relevancia inusitada.

El desacuerdo de Kropotkin con ciertas ideas de Darwin y las actitudes descalificadoras de Marx y Engels hacia Réclus también contribuyeron en la invisibilización de este enfoque. (Estebanez, J., 1992)

La geografía ecológica humana fue propuesta, en 1923, a través de un discurso -que luego tuvo una gran difusión- del presidente de la Asociación de Geógrafos Americanos, profesor Harlan Barrows (impulsor de la escuela de Chicago), quien -desde una visión marcadamente biologistaretomó algunas ideas de Ratzel para plantear esta concepción unificadora entre la naturaleza y el hombre. (Gómez Mendoza, J. et al, 1982)

Esta perspectiva no pudo afianzarse en momentos en que el peso de los enfoques general y regional era sustantivo en la ciencia geográfica, pero no obstante, dejó marcado un trazo que sería recuperado, reorientado y enriquecido por la geografía ambiental en las décadas finales del siglo XX, cuando cobraron interés las preocupaciones y problemáticas ecosistémicas y ambientales ante la creciente artificialización del espacio y la intensiva afectación antrópica de medios y recursos naturales.

La geografía cultural tuvo sus huellas en Ratzel y en Vidal de la Blache, pero fue Carl Sauer en los años ' 20 (del siglo XX) quien colocó en el escenario geográfico la llamada "morfología del paisaje" en la escuela de Berkeley (California). Esta perspectiva fue dimensionándose en las décadas siguientes. Postulaba, desde una concepción opuesta al determinismo y al positivismo, que los paisajes

Publicado en formato digital: Dr. Dante Edin Cuadra. LOS ENFOQUES DE LA GEOGRAFíA EN SU EVOLUCIÓN COMO CIENCIA. Revista Geográfica Digital. IGUNNE. Facultad de Humanidades. UNNE. Año 11. № 21. Enero - Junio 2014. ISSN 1668-5180 Resistencia, Chaco.

En: http://hum.unne.edu.ar/revistas/geoweb/default.htm 
culturales son creados a partir de formas superpuestas al paisaje natural y, por tanto, debían estudiarse a través de caminos inductivos y de análisis de las particularidades cimentadas en el trabajo de campo. Ello significaba entender la intervención humana en el medio, la construcción de los paisajes culturales y la influencia que ellos tienen en las formas de vida y en las organizaciones humanas, considerando su historicidad. En la visión saueriana, el espacio geográfico era abordado desde una dimensión estrictamente material de la cultura.

\section{Los enfoques geográficos posteriores a la segunda guerra mundial}

En el itinerario de la ciencia geográfica se observa que los enfoques no surgen para luego desaparecer, sino que -con mayor o menor protagonismo- logran convivir con las restantes perspectivas tradicionales y con las más recientes. Incluso, algunos enfoques adoptan un estado semejante a la hibernación en ciertas etapas y, luego, despiertan y logran recuperar fuerzas, a veces cambiando su denominación, pero manteniendo su esencia. Para darle una designación adecuada a la dinámica propia que caracteriza a la geografía, al menos desde fines del siglo XIX hasta el presente, debería hablarse de una "coexistencia de gravitaciones relativas de distintos enfoques".

El fin de la segunda contienda mundial, en 1945, permitió ver la caótica realidad de muchos espacios geográficos afectados y las propias limitaciones de los enfoques geográficos vigentes por entonces. Países devastados, economías quebradas, campos improductivos, ciudades diezmadas, servicios interrumpidos, ambientes deteriorados, poblaciones hambrientas, falta de trabajo y de viviendas, problemas de comunicación y, por tanto, de provisión -debido al bombardeo sobre rutas, puentes, puertos y aeropuertos- era el panorama exhibido en gran parte de Europa, con inevitables implicancias en todo el mundo. Los enfoques geográficos más encumbrados hasta allí habían sido la geografía general y la geografía regional (esta última logró jerarquizarse y ejercer fuerte influencia durante los años transcurridos del siglo $X X)$, pero ninguna de ellas estaba en condiciones de brindar las soluciones que reclamaba el momento histórico. La fragmentación de la primera y la debilidad teórica y, por qué no, metodológica de la segunda las colocaron a inferior altura de la que exigían las circunstancias.

En este contexto surgió la geografía cuantitativa neopositivista, con una fuerte crítica hacia la perspectiva regionalista (historicista-posibilista), postulando técnicas y procedimientos objetivos, un vocabulario lógico-matemático universal amparado en la estadística y la probabilidad y, esperanzadoramente, con la capacidad de elaborar modelos que rápidamente reorganizarían al mundo colapsado. El libro Excepcionalismo en Geografía del cuantitativista Fred Schaefer, del año 1953, ofició de lanzamiento del enfoque cuantitativo en Estados Unidos, constituyéndose al mismo tiempo en una fuerte descalificación a la geografía regional y, en cierta manera, a su representante estadounidense Richard Hartshorne. En Reino Unido fue el Grupo de Bristol (Peter Haggett, Richard Chorley y David Harvey) el encargado de promover y difundir este enfoque en la década de 1960, en tanto en Francia no tuvo demasiado eco hasta 1970 debido a la resistencia esgrimida por la escuela regionalista. (Estebanez J., 1992)

Si bien la geografía cuantitativa ocupó gran parte del escenario (investigaciones, congresos, publicaciones) durante las décadas de 1950 y de 1960, no se produjo la eliminación de la geografía regional, ni mucho menos, pues ésta seguía teniendo peso en Francia y en otros países, entre ellos Argentina, hasta los años '80.

La geografía cuantitativa (también llamada teórica, analítica, teorética y locacional) no fue la panacea que muchos esperaban y, pronto, comenzó a perder imagen ante su ineficacia para resolver los problemas del espacio, la frialdad de sus análisis y la cosificación del hombre, aunque pudo sostenerse a través del tiempo por la demanda que han tenido sus técnicas en un mundo saturado de datos, producto del desarrollo tecnológico.

La geografía sistémica tuvo como contexto a la Teoría General de Sistemas enunciada por Ludwig von Bertalanffy a fines de los '60, la cual logró afianzarse en los años '70 en las ciencias naturales y exactas, aunque encontramos antecedentes de esta teoría en Hans Reichenbach, quien integraba el Grupo de Berlín (confesamente neopositivista). En las ciencias sociales y, particularmente, en la geografía llegó más tardíamente logrando una importante aceptación en las ramas física, ambiental y, más someramente, en geografía humana.

Publicado en formato digital: Dr. Dante Edin Cuadra. LOS ENFOQUES DE LA GEOGRAFÍA EN SU EVOLUCIÓN COMO CIENCIA. Revista Geográfica Digital. IGUNNE. Facultad de Humanidades. UNNE. Año 11. No 21. Enero - Junio 2014. ISSN 1668-5180 Resistencia, Chaco.

En: http://hum.unne.edu.ar/revistas/geoweb/default.htm 
Su enfoque holístico e integrador y la posibilidad de abordar al espacio geográfico como un sistema (reconociendo elementos o subsistemas, conexiones, organización interna, ingresos, egresos, tiempos de respuestas, retroalimentación positiva y negativa, equilibrio dinámico, inercia, memoria y otros conceptos) fácilmente esquematizable y comprensible, aunque simplificador de la realidad compleja que representa el espacio geográfico, lo llevó a ser depositario de la preferencia de muchos geógrafos. (Popolizio, E., 1987)

Como enfoque encolumnado en el paradigma neopositivista, recibió críticas semejantes a las padecidas por la geografía cuantitativa. No obstante, esta perspectiva y su metodología siguen teniendo aplicación en diversas temáticas geográficas como geomorfología, hidrografía, climatología, biogeografía, geografía urbana, rural y económica.

La geografía cultural, impulsada por Sauer, siguió teniendo cierta relevancia en Estados Unidos hasta los años ' 50 y '60, cuando fue eclipsada por los nuevos enfoques. Entre los años '70 y los '90 tomó la posta Paul Claval en Francia, resignificándola y admitiendo la existencia de componentes no solamente materiales, sino simbólicos en el espacio geográfico. Desde los años ' 80 en adelante, sobre todo en Reino Unido y Estados Unidos se ha desarrollado un matiz diferente de la geografía cultural desde una perspectiva neomarxista apoyada en el materialismo histórico (dialéctica), enriquecida con los aportes de pensadores posmodernos como Derrida, Foucault y Lyotard, entre otros. En esta perspectiva cultural posmoderna cobran interés los aspectos simbólicos, discursivos e identitarios del espacio, el lugar como ámbito de poder (territorialidad) y donde se gestan los significados culturales. Desde la geografía han abonado a esta nueva versión de la geografía cultural autores como Harvey, Massey, Soja, Cosgrove y Haesbaert. En los últimos años este enfoque renovado, a veces fusionado o confundido con las tendencias críticas humanista y radical, ha alcanzado un rol protagónico en congresos y publicaciones. Al tratarse de un enfoque en formación, aún le falta desarrollo teórico y metodológico y, por cierto, exhibir resultados concretos, pues en gran medida sigue siendo una postura crítica y meramente propositiva; sus consistencias se encuentran en pleno debate y sus temáticas se hallan muy diversificadas, a veces discordantes y en conflicto.

De la mano de la escuela psicológica conocida como Conductismo, en la década de 1960, se desarrolló la perspectiva conocida como la geografía de la percepción y el comportamiento, aunque sus bases ya estaban en construcción en la década anterior, gracias a los aportes de Kenneth Boulding. Esta nueva mirada centró su interés en las maneras en que el espacio se representa en la percepción de los individuos, es decir, en la imagen mental individual y colectiva (mapas mentales) que sobre su entorno desarrollan los seres humanos y que impulsan sus respuestas o comportamientos en el espacio. (Estebanez, J., 1992).

Esta concepción de un espacio percibido, sentido y vivido incorporó parámetros subjetivos, en disconformidad con el hombre-objeto-número-cosa que se postulaba desde la geografía cuantitativa, la cual -casi siempre- sobredimensionaba al componente económico en sus análisis. Se superaron así las limitaciones impuestas por ideas irreales como la de la racionalidad absoluta o la de los espacios isotrópicos.

No obstante su procedencia social e histórica, la perspectiva de la percepción y el comportamiento se valió de herramientas cuantitativas y, más precisamente, estadísticas para la recopilación y procesamiento de los datos, como las encuestas, muestreos y la aplicación de correlaciones. Su gran aporte fue la participación del ciudadano común con sus gustos, preferencias y rechazos, es decir, la aceptación y rescate de las subjetividades (sentimientos, emociones, vivencias) en el quehacer científico, pero además, como insumo para la planificación del espacio geográfico.

La geografía radical apareció en escena a fines de la década de 1960, pero recién en los años '70 logró consolidarse como una reacción férrea llevada a cabo por los defensores de las ideologías de izquierda, sobre todo marxistas, contra el cuantitativismo promovido en los países capitalistas (neoliberales). (Estebanez, J., 1992)

Abogaron por una manera comprometida de hacer geografía en la sociedad y no al servicio de los poderes dominantes o de las potencias hegemónicas y denunciaron las omisiones que las posturas positivistas mostraban exprofeso en sus producciones.

Propugnaban enfocar la geografía hacia los problemas sociales y la búsqueda de soluciones ante injusticias, inequidades y asimetrías, retomando las ideas de fines del siglo XIX enunciadas por

Publicado en formato digital: Dr. Dante Edin Cuadra. LOS ENFOQUES DE LA GEOGRAFÍA EN SU EVOLUCIÓN COMO CIENCIA. Revista Geográfica Digital. IGUNNE. Facultad de Humanidades. UNNE. Año 11. $N^{0}$ 21. Enero - Junio 2014. ISSN 1668-5180 Resistencia, Chaco.

En: http://hum.unne.edu.ar/revistas/geoweb/default.htm 
Réclus y Kropotkin. Ya en la década de 1980, gracias a las contribuciones de geógrafos como Yves Lacoste, Milton Santos y David Harvey este enfoque crítico ganó relevancia dentro de la comunidad científica, colocando en la palestra una nueva concepción de espacio, entendido éste como una construcción social, un producto que se genera en la historia que la sociedad produce y reproduce.

La geografía humanista, también proveniente de la corriente crítica, representó en la década de 1970 un movimiento más flexible y abierto respecto del enfoque radical, capaz de abrevar en doctrinas de izquierda, socialistas, cristianas, idealistas, fenomenológicas y existencialistas. (Estebanez, J., 1992). Ambas perspectivas, humanista y radical, colocaron al hombre en el centro de sus preocupaciones (concepción antropocéntrica), pero en el caso de la geografía humanista el énfasis fue puesto en aspectos trabajados anteriormente por la geografía cultural y por la geografía de la percepción y el comportamiento. De este modo, tomó fuerza el concepto de "lugar" como espacio vivido cargado de simbolismos, relaciones sociales, valorizaciones y significados emocionales (sentimientos) que hacen al arraigo y a la identidad que desarrollan los seres humanos y la comunidad humana en diferentes sitios de la superficie terrestre. Los aportes de Yi-Fu Tuan a través de conceptos como "topofilia", "topofobia", "topolatría", "lugar" y el aporte de Marc Augé sobre la idea de los "no lugares" fueron muy significativos para este nuevo enfoque geográfico que intenta comprender al espacio geográfico desde la representación que los seres humanos se hacen de él o, en palabras de Tuan, desde "...la percepción y evaluación del entorno por parte de la gente, así como el impacto del entorno en la gente" (Tuan, Y.-F., 2007).

La geografía ambiental, que embriológicamente tuvo presencia en la etapa griega y apariciones discontinuas desde el siglo XVIII en adelante, ha mostrado dificultades en perpetuarse, en parte por la visión fragmentaria y dicotómica que padeció la disciplina al abordarse la geografía física y la geografía humana como campos separados (muchas veces infranqueables) por parte del enfoque general y sistemático. El aporte de los regionalistas de la escuela francesa, luego -en la década de 1920- la propuesta de H. Barrows empleando el concepto de "ecología humana" y, más tarde, el impulso cobrado por el enfoque sistémico, ayudaron a poner el énfasis sobre las relaciones sociedadnaturaleza. Esta visión más holística y relacional fue retomada por la geografía en las décadas de 1980 y 1990, ante los estragos que la sociedad tecnológica y consumista generaba a nivel ambiental. Esta percepción y toma de conciencia de las problemáticas ambientales llevó a muchos países, entre ellos Argentina, a implementar cambios normativos, institucionales, educacionales y de praxis política, económica y jurídica, con la finalidad de preservar áreas naturales y, además, evitar, mitigar o resolver los impactos (disturbios o efectos adversos) sobre los ecosistemas y los propios grupos humanos.

La geografía ambiental, alineada con otras disciplinas, ha contribuido enormemente en materia educativa, en la concienciación social, en la investigación, en estudios y en evaluaciones ambientales, con el objetivo de prevenir, reducir y solucionar problemáticas concretas en espacios geográficos de diferentes países.

La llamada geografía automatizada es una resultante, en el campo de la geografía, del contexto o paradigma tecnológico informático, digital, satelital y redificado (edificado en red) que caracteriza a nuestro mundo "global". Más allá de las discusiones acerca de si la geotecnología es o no un paradigma o los debates sobre si la geografía automatizada constituye un enfoque geográfico o se trata meramente de un 'conjunto de herramientas y técnicas amalgamadas por una teoría en formación` utilizadas por otras perspectivas geográficas (y por diversas disciplinas), en este trabajo se aborda a la geografía automatizada como un enfoque geográfico (en conformación).

Desde 1980 se viene acelerando e intensificando la carrera por la automatización de los procedimientos de análisis espacial, produciéndose un salto en la revalorización de la dimensión espacial de forma generalizada, con alto impacto en el resto de las disciplinas científicas, motivo por el cual se habla de la geografía global. (Oropeza, M. y Díaz, N., 2007).

Para Buzai la geotecnología, más que un enfoque, constituye un paradigma y lo explica de la siguiente manera en su tesis doctoral: "La Geotecnología presenta una nueva forma de ver el mundo. Una nueva forma de ver la realidad que la Geografía le provee al resto de las disciplinas. Bajo estas consideraciones el Paradigma Geotecnológico tiene existencia, pero no como paradigma de la Geografía, sino como paradigma Geográfico de alcance interdisciplinario y al servicio total del

Publicado en formato digital: Dr. Dante Edin Cuadra. LOS ENFOQUES DE LA GEOGRAFÍA EN SU EVOLUCIÓN COMO CIENCIA. Revista Geográfica Digital. IGUNNE. Facultad de Humanidades. UNNE. Año 11. $N^{0}$ 21. Enero - Junio 2014. ISSN 1668-5180 Resistencia, Chaco.

En: http://hum.unne.edu.ar/revistas/geoweb/default.htm 
hombre. En síntesis, la Geografía explota hacia el resto de las disciplinas a través de la Geografía Global y sus conceptos se incluyen en el interior de la Geotecnología como formadora del Paradigma Geotecnológico, no como un paradigma de la Geografía sino como un paradigma geográfico". (Buzai, G., 1998)

\section{Distintas interpretaciones sobre la evolución de la geografía como ciencia}

En primer lugar, debe quedar claro qué son los paradigmas dentro de la ciencia. Los paradigmas son modelos, preceptos o concepciones (cosmovisiones) acerca de los modos, procedimientos, métodos y respuestas que la ciencia debe dar a los temas y problemas de una época. Un paradigma es generado en el interior de una sociedad o cultura y, por tanto, en un determinado contexto temporal y espacial, de manera que si logra captar adeptos dentro de la comunidad científica (establishment) puede ejercer influencia o regir la actividad científica.

Varios pensadores, filósofos y epistemólogos han tratado de entender cómo evolucionan las ciencias, aunque no siempre sus apreciaciones guardan coincidencias. Algunos de ellos han sido:

Thomas Kuhn: según este filósofo estadounidense, las ciencias se desarrollan en fases: un primer momento, de "ciencia normal", que goza de consenso en la comunidad científica sobre los problemas existentes, creándose así soluciones universales que el autor llama "paradigmas". Cuando éstos sufren dificultades y se encuentran con refutaciones que no logran superarse, se inicia un estado de "crisis", la que se resuelve con el surgimiento de un "nuevo paradigma" que va fortificándose dentro de la comunidad científica, hasta abandonarse el paradigma original abrumado por problemas que no puede resolver. Este cambio se efectúa durante una "revolución científica" y, a partir de ese momento, el nuevo paradigma guía la actividad científica normal hasta la aparición de una nueva crisis. Al postulado de Kuhn se lo podría denominar "teoría de la imposición y el reemplazo de un paradigma por otro".

Imre Lakatos: para este filósofo húngaro, la ciencia tiene una dinámica semejante a un litigio entre tres contendientes: dos teorías y un experimento. El mayor interés está puesto en la confirmación de una de las teorías y no en su falsificación. Para él, lo usual es que cuando falla alguna de las predicciones derivadas de una teoría, ésta no se excluye, sino que se conserva mientras se afinan las observaciones realizadas y se llevan a cabo otras, conociéndose esa situación como "anomalía". Éstas no suelen ser una rareza, sino un hecho bastante repetitivo en el comportamiento de las ciencias y, por esa razón, no conviene descartar una teoría ni bien surja una experiencia que la contradiga, dado que es preferible una teoría -aún con anomalías- que carecer de ella. En consecuencia, sólo se descarta una teoría cuando se comprueba que hay otra que ofrece mayor contenido empírico e igual o mayor riqueza explicativa. A esta postura podría llamársela "puja de teorías con convivencia transitoria o imposición de una de ellas".

Raúl Rey Balmaceda: desde la óptica de este geógrafo argentino, existen dos procesos en paralelo en la evolución de la ciencia geográfica, que son: a) "la teoría de la evolución lineal o cronológica": por acumulación de saberes y descubrimientos a lo largo de su historia; b) "la teoría de la coexistencia de dos paradigmas": en contraposición con lo enunciado por Kuhn, asevera que en la historia de la ciencia geográfica se observa que un paradigma no sustituye a otro, pasando por crisis y revoluciones científicas, sino que el que surge se suma y convive -con mayor o menor fricción- con el que ya existía.

Silvia Santarelli y Marta Campos: estas geógrafas argentinas sostienen que “...los paradigmas coexisten en una continuidad de ideas y, progresivamente, la comunidad científica adopta aquel que ofrece mayor seguridad o respuestas; desde esta posición es pertinente aclarar que la noción de paradigma no se entiende literalmente como ruptura o revolución, tal el punto de vista de Kuhn (1985)". Además, expresan: "...es factible sintetizar la historia de la epistemología de la Ciencia Geográfica en períodos signados por concepciones filosóficas que surgen -en algunos casos y del mismo modo que para la Ciencia en general- como reacción al conjunto de paradigmas predominantes... Así, desde la segunda mitad del siglo XIX se observa el predominio de posturas positivistas, intercaladas y opacadas por reacciones "historicistas" y, más adelante behavioristas o humanistas". "Las diferentes ópticas de análisis conllevan, entonces, una serie de dicotomías, que en el proceso de consolidación de la Geografía se repiten sistemáticamente pues responden al paradigma dominante en cada período". (Santarelli S. y Campos M., 2002)

Publicado en formato digital: Dr. Dante Edin Cuadra. LOS ENFOQUES DE LA GEOGRAFÍA EN SU EVOLUCIÓN COMO CIENCIA. Revista Geográfica Digital. IGUNNE. Facultad de Humanidades. UNNE. Año 11. $N^{0}$ 21. Enero - Junio 2014. ISSN 1668-5180 Resistencia, Chaco.

En: http://hum.unne.edu.ar/revistas/geoweb/default.htm 
A esta apreciación evolutiva de la geografía podría llamársela "teoría de la coexistencia de paradigmas con alternancia de dominadores".

Gustavo Buzai: este geógrafo argentino entiende que el pensamiento geográfico, durante gran parte del siglo $X X$, ha mostrado ciclos en los que se alterna la influencia positivista e historicista a través de enfoques que responden a uno $u$ otro paradigma.

Este autor se aventura a interpretar lo que, desde su óptica, estaría ocurriendo con la evolución del pensamiento geográfico en la parte final del siglo pasado e inicios del XXI, introduciendo una lectura prospectiva de la cuestión. En tal sentido, Buzai advierte una convergencia de la geografía críticamarxista y de la geografía humanista-posmoderna (Historicismo) con la geografía automatizada y la ecología de paisajes (Positivismo) que conduciría a la constitución de un paradigma geográfico: la geotecnología. No obstante, admite que "Los conceptos geográficos que sustentan la Geotecnología, los conceptos técnicos utilizados para el tratamiento de la información y los casos de estudio seleccionados muestran claramente que la Geotecnología no puede, por si sola, conformar un campo para la formulación de teorías e hipótesis de trabajo y, solamente, podría ser considerado un nuevo paradigma desde el punto de vista de su perspectiva de representación empírica en un nuevo ambiente. En este sentido se presenta como campo difuso. Por lo tanto, se puede conceptualizar que la Geotecnología se presenta en un primer nivel, principalmente como ambiente para la revalorización paradigmática de las posturas filosóficas que permitieron su sustento: el Paradigma Racionalista y el Paradigma Cuantitativo. Por lo tanto, la Geotecnología permite un avance como nueva visión paradigmática de la Geografía con características que vislumbran su formulación, y su posición en la disciplina es compartida actualmente con los desarrollos del Landscape Ecology y la Postmodern Geography que revalorizan -bajo sus mismas perspectivas- a las restantes posturas paradigmáticas ya analizadas". "Sin embargo, el impacto de la Geotecnología en el resto de las disciplinas científicas es notable, a tal punto que ha revalorizado la dimensión espacial de forma generalizada incluyendo conceptos geográficos fundamentales que permiten "hacer geografía" a quienes no son geógrafos. En este sentido ha surgido lo que hemos denominado la Geografía Global, es decir, la Geografía difundida a través de los medios informáticos. Esta Geografía Global permite definir una suerte de explosión disciplinaria como una expansión irreversible de impacto interdisciplinario. (Buzai, G., 1998)

A esta postura, se la podría denominar, al menos en gran parte de su itinerario, "teoría cíclica de paradigmas", tal como se aprecia en el siguiente esquema:

Figura № 1:

\section{Ciclos del pensamiento geográfico}

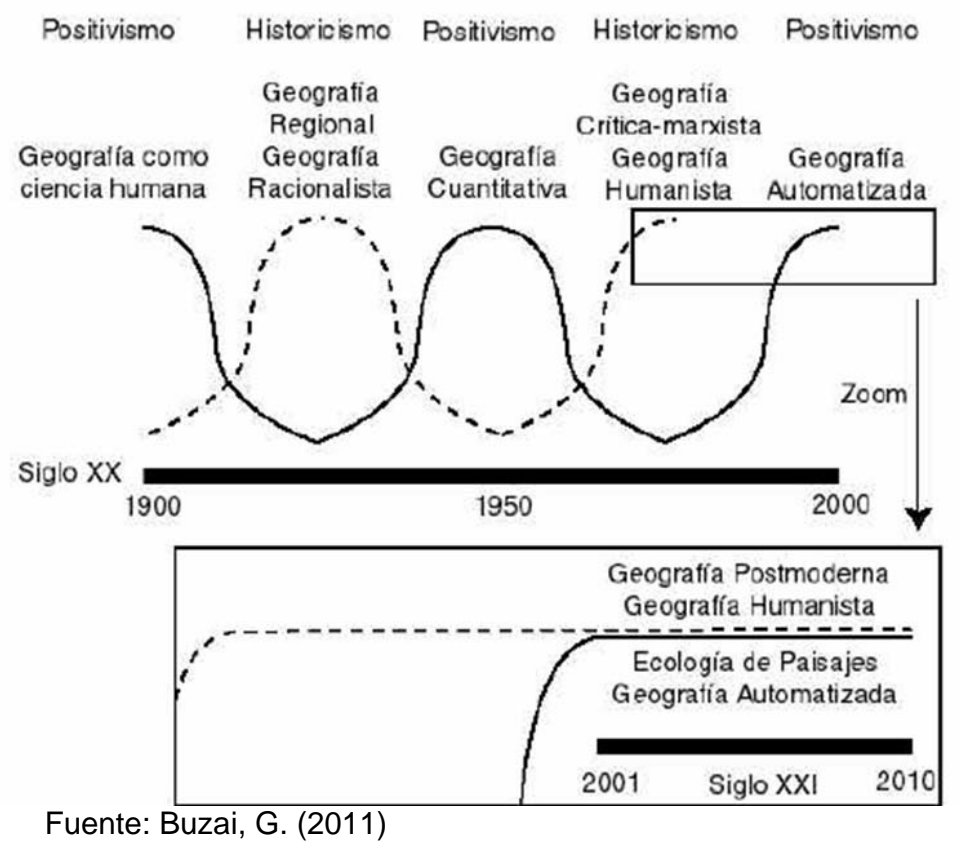

Publicado en formato digital: Dr. Dante Edin Cuadra. LOS ENFOQUES DE LA GEOGRAFíA EN SU EVOLUCIÓN COMO CIENCIA. Revista Geográfica Digital. IGUNNE. Facultad de Humanidades. UNNE. Año 11. No 21. Enero - Junio 2014. ISSN 1668-5180 Resistencia, Chaco.

En: http://hum.unne.edu.ar/revistas/geoweb/default.htm 
Del análisis realizado sobre las diferentes posturas esgrimidas por los autores citados, queda claro que lo que ha ocurrido en geografía, al menos desde fines del siglo XIX a nuestros días, ha sido "la coexistencia de gravitaciones relativas de dos o más enfoques adheridos al paradigma positivista o al historicista (o socio-histórico)". Esos enfoques se amparan en diversas teorías, modelos, doctrinas o filosofías, muchas de ellas surgidas durante el siglo XX y lo que va del XXI, que les sirven de contexto epistemológico que, con amplitud de criterio, pueden ser agrupados en el interior de los dos grandes paradigmas mencionados.

\section{Paradigmas y enfoques}

El concepto de paradigma ya ha sido expuesto en párrafos anteriores y da idea de teorías, doctrinas o enunciados filosóficos que representan un contexto, una visión del mundo y una referencia (una brújula) para orientar la actividad científica. Por tanto, un paradigma trasciende a una disciplina, se dimensiona social y culturalmente e influye en una parte o en la totalidad de los campos científicos. Sin embargo, un enfoque (también puede aparecer en la literatura con los nombres de perspectiva, óptica, tendencia, corriente, pedestal o escuela) se conforma en el interior de una disciplina, generalmente como respuesta, asimilación o adecuación a una influencia paradigmática. Esta influencia puede ser prolongada, breve u ofrecer altibajos según la surgencia o resurgencia de otro/s paradigma/s. En este sentido, un paradigma representa una mirada distinta, brinda atención y resolución a cuestiones preocupantes científica y socialmente, a la vez que propone, instala o recupera temáticas de investigación atractivas y desafiantes para la comunidad científica.

En la Edad Antigua (griegos) surgieron varios paradigmas, algunos impulsados por filósofos o pensadores que llegaron a constituir verdaderas escuelas, con discípulos y seguidores. Por ejemplo, el paradigma idealista de Platón (Atenas), el geocéntrico de Ptolomeo (Alejandría), el empirista de Aristóteles (Atenas) y Eratóstenes (Alejandría) y el algorítmico o numerológico de Pitágoras (primero en la isla de Samos en Asia Menor y, luego, en la Magna Grecia situada en el Sur de Italia). No había enfoques muy definidos, pues no existían fronteras visibles entre las disciplinas; se podría hablar de un enfoque enciclopédico o multitemático, aunque es posible reconocer allí las improntas de la geografía regional en Heródoto y Estrabón o de la geografía ambiental en Ptolomeo y Estrabón. Este último, con su obra "Geografía" coronó el rigor descriptivo que caracterizó a este campo del saber durante mucho.

En la Edad Media se puede hablar de una cosmovisión o paradigma teocéntrico en Europa católica, que dio paso a un enfoque literario o artístico-religioso en el abordaje del espacio geográfico (mezcla de realidad con fantasía, género imaginativo), a diferencia de los árabes (Al Idrisi, Batuta y Jaldún), que se apoyaban en los viejos paradigmas recuperados de los griegos y les sumaron innovaciones (productos de sus viajes, cálculos y mapas), por lo que podría tratarse de un enfoque exploratorio de carácter descriptivo.

La geografía general (enfoque que atravesó la Edad Moderna y Contemporánea), se sustentaba en el paradigma antropocéntrico (en contraposición al teocéntrico), con fuerte tenor nacionalistacolonialista. Más tarde, ya avanzada la Edad Contemporánea (siglo XIX), la geografía general se ató al paradigma positivista y a las doctrinas naturalista, evolucionista y determinista que se ensamblaban en él. Aún Ratzel, el gran defensor e impulsor de la geografía humana, estuvo marcado por esas concepciones.

La geografía regional (perspectiva que tomó forma hacia 1880, es decir, en plena Edad Contemporánea) se apoyó en el paradigma historicista y en la doctrina del posibilismo (enunciada por el historiador francés Lucien Febvre, inspirado en el "anti-determinismo ambiental" expuesto por Vidal de la Blache). De esa manera, el enfoque regional se despegó del determinismo y de la generalización (camino nomotético), para concebir al espacio desde una visión idiográfica como unidad geográfica diferenciada resultante de procesos históricos.

Como se ha visto, desde mediados del siglo XIX han sido dos los grandes paradigmas que ejercieron influencia sobre la geografía: a) el positivismo (enunciado por Comte), que a mediados del siglo XX mostró algunas innovaciones y se lo reconoce como neopositivismo; b) el historicismo (sintetizado por Dilthey), que vino a ser un punto intermedio entre el positivismo y el idealismo, concibiendo que lo que se aprecia en la sociedad y en el espacio es resultado del devenir histórico.

Publicado en formato digital: Dr. Dante Edin Cuadra. LOS ENFOQUES DE LA GEOGRAFíA EN SU EVOLUCIÓN COMO CIENCIA. Revista Geográfica Digital. IGUNNE. Facultad de Humanidades. UNNE. Año 11. $N^{0}$ 21. Enero - Junio 2014. ISSN 1668-5180 Resistencia, Chaco.

En: http://hum.unne.edu.ar/revistas/geoweb/default.htm 
A partir de la segunda mitad del siglo $X X$ ha proliferado una gran cantidad de teorías, modelos y marcos conceptuales que podrían -en líneas generales- agruparse dentro de uno u otro paradigma, a los que se podrían denominar:

a) Positivista-Neopositivista: el positivismo como doctrina filosófica sostiene que la razón y la ciencia constituyen las únicas guías de la humanidad para lograr el orden social, excluyendo los argumentos teológicos y metafísicos. La observación empírica es el camino para identificar y explicar el comportamiento de los hechos, apuntando a la formulación de leyes y aplicando un solo método para todas las ciencias. A mediados del siglo XX, gracias a los aportes de los miembros del Círculo de Viena y del Grupo de Berlín, esta doctrina se renovó en ciertos aspectos y se la reconoció como neopositivismo: dejó de ser excluyente la metodología inductiva e incorporó los procesos hipotéticodeductivos, se apartó de la unicidad causal y apostó a la probabilidad, a los efectos de que las leyes y teorías fueran más sustentables.

b) Socio-histórico: en realidad esta nominación representa un alto grado de generalización, pues se trata de un conjunto que incluye un gran número de concepciones o paradigmas que tienen por denominador común al hombre, a la sociedad y a la temporalidad. El historicismo vendría a ser la doctrina pionera, pero también integrarían este grupo el posibilismo, el paradigma interpretativo (anticipado por Dilthey al sostener que las ciencias exactas y naturales explican y las ciencias del hombre comprenden o interpretan), el conductismo, el marxismo y las diversas teorías sociales que han ido surgiendo, sobre todo, en las últimas décadas.

Un amplio abanico de teorías, modelos, filosofías, doctrinas e ideologías vendrían a oficiar de nexo o interface entre los enfoques de una ciencia y el o los paradigma/s vigente/s, tal como se ejemplifica en el cuadro que sigue. Se entiende, entonces, que el paradigma trasciende el nivel escalar de una ciencia, se instala como contexto, como marco referencial y, por tanto, incide sobre un conjunto o la totalidad de las ciencias. Esa influencia es direccionadora a nivel de los conceptos, planteos, problemas, temas, métodos, técnicas y modalidades de abordar el objeto de estudio y de desarrollar los procesos investigativos. Por tal motivo, en el interior de las ciencias influidas se produce una aceptación y adecuación a la nueva concepción y, así, surge un nuevo enfoque que puede coexistir o, en oportunidades, tomar el liderazgo e, incluso, opacar a los demás enfoques. Al respecto, Fernández Caso afirma: "...una de las tendencias de las ciencias sociales actuales es reconocer y respetar la coexistencia de diferentes enfoques..." (Fernández, Caso, M. V., 2009), en tanto, Blanco sostiene que "El concepto de espacio geográfico se presta a distintas interpretaciones y perspectivas". (Blanco, J., 2009)

Figura № 2:

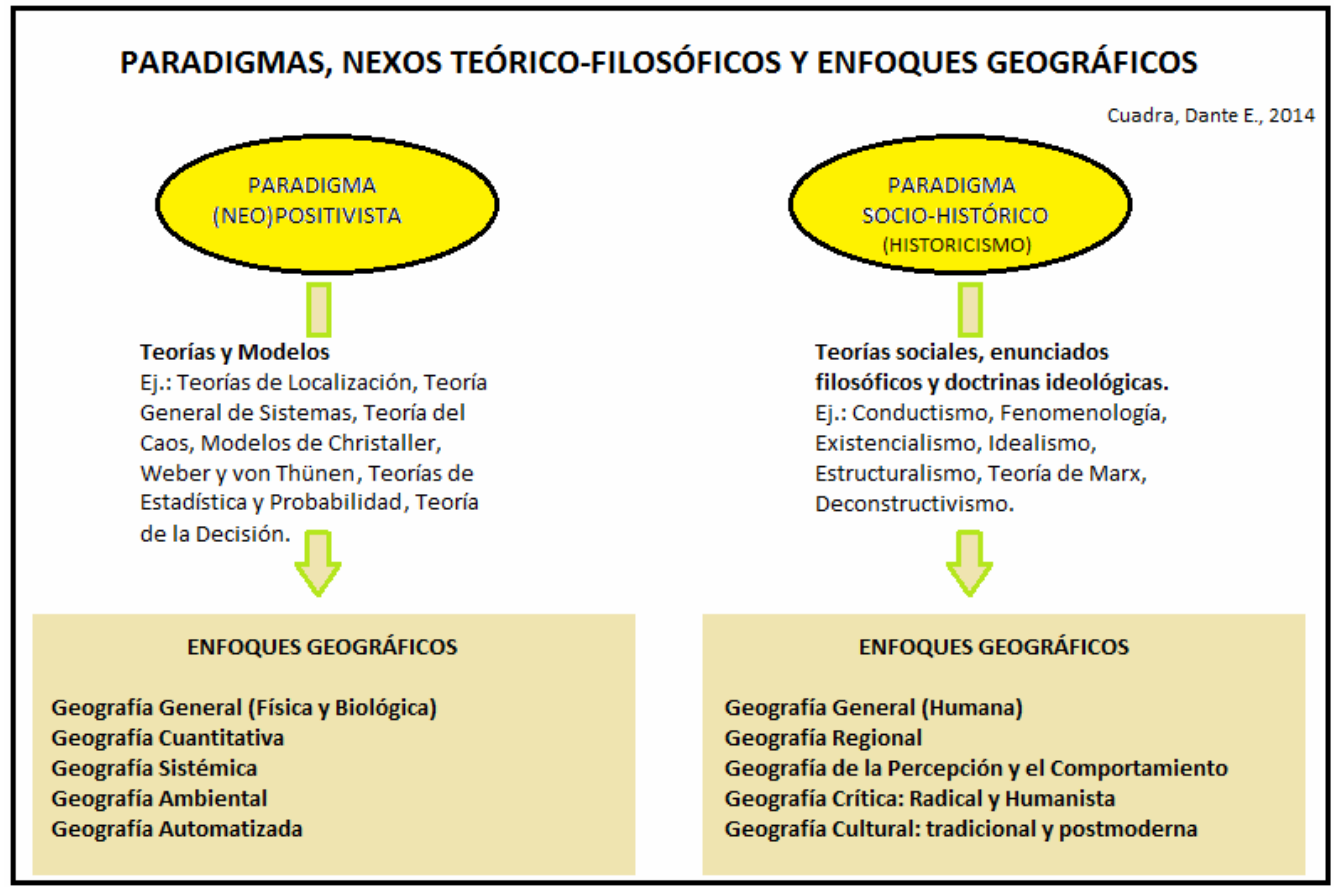

Publicado en formato digital: Dr. Dante Edin Cuadra. LOS ENFOQUES DE LA GEOGRAFÍA EN SU EVOLUCIÓN COMO CIENCIA. Revista Geográfica Digital. IGUNNE. Facultad de Humanidades. UNNE. Año 11. $N^{0}$ 21. Enero - Junio 2014. ISSN 1668-5180 Resistencia, Chaco.

En: http://hum.unne.edu.ar/revistas/geoweb/default.htm 
No se puede negar la existencia de dominancias de uno $u$ otro paradigma (positivismo y sociohistórico) en el transcurso del tiempo, pero lo que se observa, además, es la coexistencia de un creciente número de enfoques en geografía, sobre todo desde mediados del siglo XX a nuestros días, los cuales se contextualizan y se enlazan con uno u otro paradigma. Ello significa que no se cumple en nuestra ciencia el postulado de Khun, que un paradigma desplaza o elimina a otro tras una revolución y crisis científica, sino lo observado por Rey Balmaceda, vale decir, la coexistencia de dos paradigmas.

Sin atribuirle valoraciones numéricas, ni jerarquías a los enfoques, el siguiente esquema permite visualizar la dinámica o la evolución de las distintas perspectivas geográficas desde fines del siglo XVIII hasta el presente. Todas ellas tienen presencia en los ámbitos académicos, en la docencia, en la investigación, en los congresos y en las publicaciones. La contemporaneidad se da con distintas gravitaciones de los enfoques dentro del campo geográfico, adquiriendo alguno o algunos de ellos mayor protagonismo y adhesión entre los geógrafos según los contextos socio-culturales de cada época. Por ejemplo, la geografía general y sistemática fue casi monopólica desde fines del siglo XVIII hasta fines del XIX, la geografía regional tuvo un rol relevante entre 1880 y 1950 y, posteriormente, tomó consistencia la geografía cuantitativa. Ello, de ninguna manera implicó que durante el dominio de esta última tuvieran que desaparecer de la escena la geografía general y la geografía regional.

En esta dinámica coexistente se puede ganar o perder trascendencia en un mismo espacio a través del tiempo o ser contemporáneos en distintos espacios. Es una realidad que un enfoque puede hacerse fuerte en ciertas universidades, centros de investigación, regiones o países y, del mismo modo, puede ocurrir con alguno/s de los demás en otras instituciones y lugares. Contrariamente, algunas perspectivas pueden quedar recluidas en pequeños grupos dentro de instituciones o países, hasta encontrar condiciones favorables que les permitan innovarse, resignificarse y reposicionarse en el escenario geográfico, como ha ocurrido con la geografía regional o con la geografía cultural. En esa línea, Fernández Caso resalta la importancia de "...los principios de complejidad, multiperspectividad, diversidad, cambio, incertidumbre, controversia y pluralismo" en la ciencia geográfica. (Fernández Caso, M. V., 2009)

Figura No 3 :

LA COEXISTENCIA DE PERSPECTIVAS A LO LARGO DE LA EVOLUCIÓN DE LA GEOGRAFía COMO CIENCIA

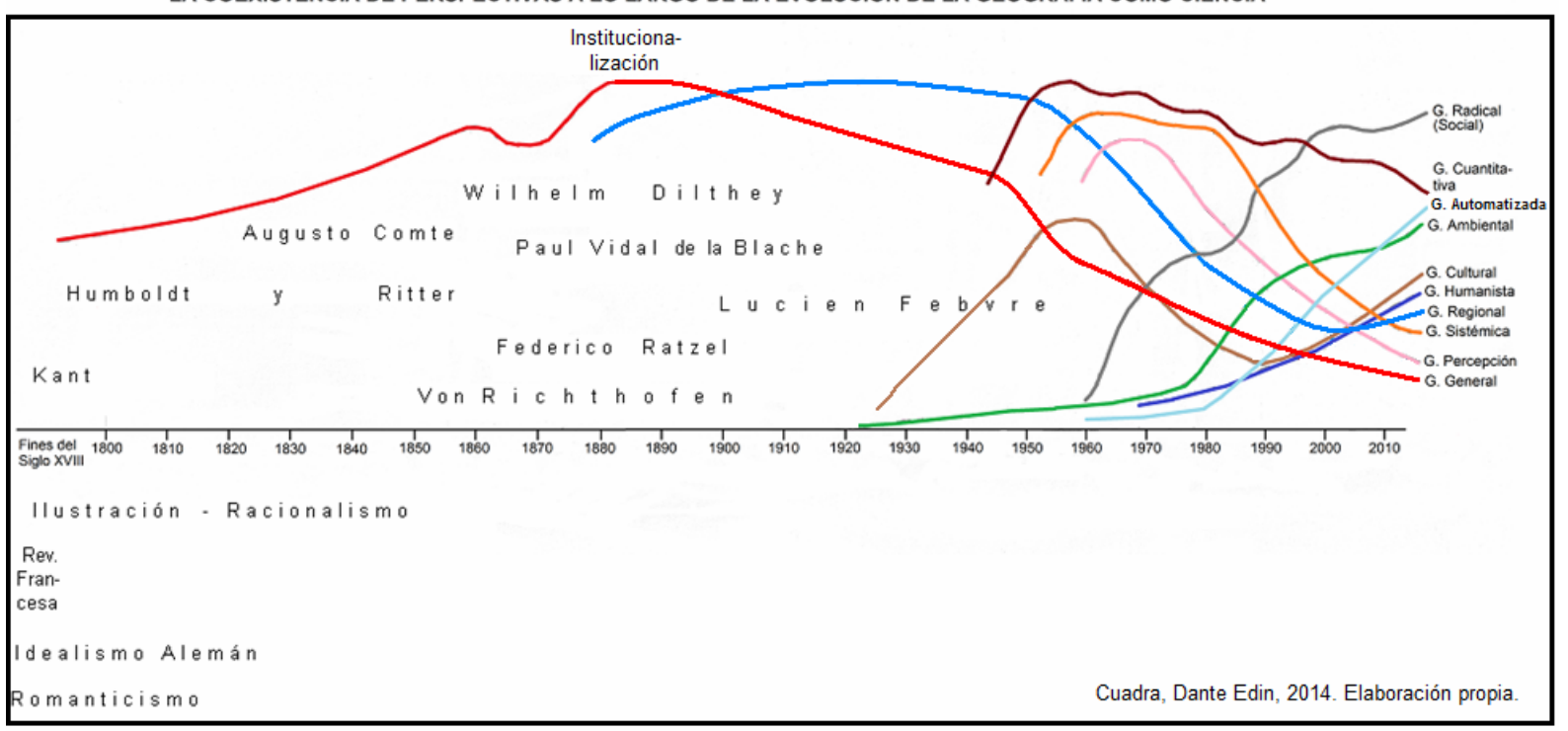

¿Por qué cada geógrafo, sea investigador, docente, planificador o gestor comunitario debería posicionarse en algún enfoque geográfico $\mathrm{y}$, por tanto, estar contextualizado por un paradigma al momento de desarrollar su tarea?. Una respuesta clara encontramos en las afirmaciones de Santarelli y Campos: "Los estudios geográficos se enmarcan en corrientes de pensamiento que, sustentadas en los diversos enfoques filosóficos actuales, proporcionan las pautas referenciales indispensables para

Publicado en formato digital: Dr. Dante Edin Cuadra. LOS ENFOQUES DE LA GEOGRAFíA EN SU EVOLUCIÓN COMO CIENCIA. Revista Geográfica Digital. IGUNNE. Facultad de Humanidades. UNNE. Año 11. № 21. Enero - Junio 2014. ISSN 1668-5180 Resistencia, Chaco.

En: http://hum.unne.edu.ar/revistas/geoweb/default.htm 
percibir e interpretar la realidad desde diferentes puntos de vista. Su conocimiento facilita asumir, de forma explícita o implícita, los modos de encarar las investigaciones y abordar problemas específicos en los marcos conceptuales, las técnicas y los métodos propios de cada perspectiva. De allí, la importancia que adquiere en la formación del geógrafo la comprensión de estas corrientes y su nexo con las nociones de modernidad y posmodernidad." (Santarelli de Serer, S. y Campos, M., 2002)

\section{A modo de síntesis: los aspectos más relevantes de cada enfoque geográfico}

En primer lugar, se hará referencia a los dos enfoques con mayor tradición, tales los casos de la geografía general-sistemática y la geografía regional, resaltando algunas características esenciales de cada uno. Luego, se hará lo propio con los enfoques enlazados con el "paradigma neopositivista" $\mathrm{y}$, finalmente, con aquéllos que tienen como contexto filosófico, teórico o ideológico a una diversidad de concepciones que podrían agruparse bajo el rótulo de "paradigma socio-histórico".

Debe tenerse en cuenta que estas agrupaciones no tienen por qué ser antagónicas o incompatibles cuando se desarrollan las investigaciones. De hecho, frecuentemente investigamos trepados a un pedestal teórico al que no abandonamos, sea por convicción teórica o ideológica, por el tipo de temas que abordamos o porque desconfiamos de la certeza o eficiencia de otros enfoques que, a veces, no conocemos en profundidad. Pero, con frecuencia observamos que, por ejemplo, desde un enfoque contextualizado en el paradigma socio-histórico se utilizan técnicas y procedimientos que provienen del enfoque cuantitativo (neopositivista). Del mismo modo, el estudio de un espacio puede abordarse desde la multiperspectiva, buscando diferentes miradas, identificando distintos problemas y, así, enriquecer el análisis y los resultados de la investigación a través de prácticas de complementación e integración.

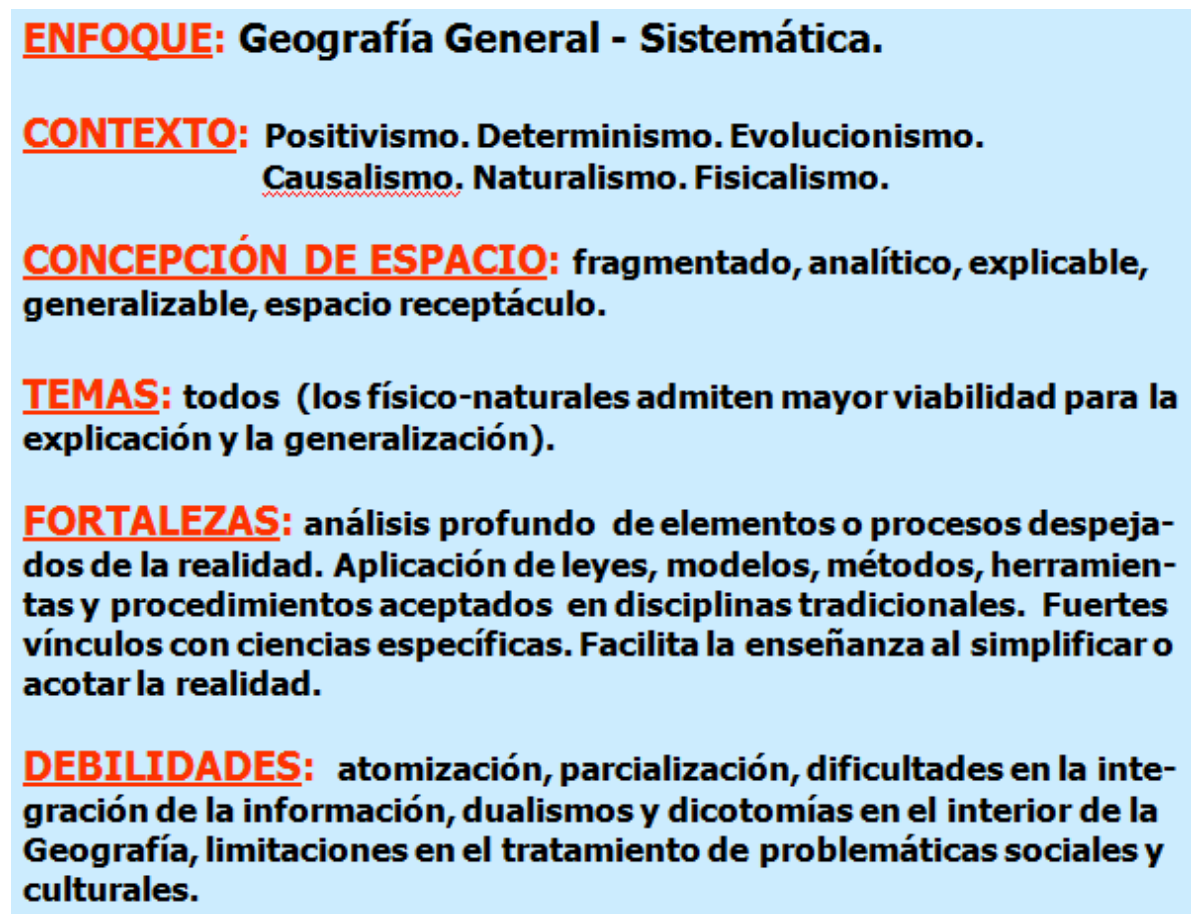

Época de surgimiento, áreas de difusión inicial y representantes destacados: tiene sus orígenes en la antigüedad, adquiriendo rigor descriptivo con la civilización griega (siglos VII a. C. hasta el II d.C.). En la edad media, los árabes hicieron aportes importantes y, en la edad moderna los países de Europa Occidental. En el siglo XVII Varenio fue un adelantado con su obra "Geografía General y Especial", pero como conocimiento científico la disciplina recién logró afianzarse a fines del siglo XVIII y, especialmente, en el siglo XIX con los aportes decisivos de Humboldt, Ritter, Ratzel y Richthofen, entre otros, y su posterior inserción en las cátedras universitarias. El área donde inicialmente la geografía logró adquirir status institucional y social como saber científico correspondió a Alemania y,

Publicado en formato digital: Dr. Dante Edin Cuadra. LOS ENFOQUES DE LA GEOGRAFÍA EN SU EVOLUCIÓN COMO CIENCIA. Revista Geográfica Digital. IGUNNE. Facultad de Humanidades. UNNE. Año 11. No 21. Enero - Junio 2014. ISSN 1668-5180 Resistencia, Chaco.

En: http://hum.unne.edu.ar/revistas/geoweb/default.htm 
luego, se sumaron los países de Europa Occidental y Estados Unidos de América, hasta difundirse en casi todo el mundo.

ENFOQUE: Geografía Regional.
CONTEXTO: Historicismo. Posibilismo.
CONCEPCIÓN DE ESPACIO: único, irrepetible, singular
(perspectiva idiográfica, mesoescala), homogéneo, fun-
cional, planificable, historizado, integrado (elementos,
combinaciones, conexiones, dinamismos).
TEMAS: unidades espaciales subcontinentales, subnacio-
nales, intraprovinciales.
FORTALEZAS: enfoque holístico, integral, énfasis en la
diferenciación de áreas y procesos, camino inductivo e
inclusivo (datos y cualidades). Síntesis. Método, medio
para la planificación y el Ordenamiento Territorial.

Época de surgimiento, áreas de difusión inicial y representantes destacados: si bien los antecedentes de la geografía regional datan de la antigüedad greco-romana (Heródoto y Estrabón) y, mucho más tarde, de Varenio (geografía especial), puede decirse que la forma acabada la obtuvo con Paul Vidal de la Blache en Francia hacia los años '80 del siglo XIX, sumándose más tarde las contribuciones de Lucien Febvre (doctrina del posibilismo) y los discípulos de Vidal de la Blache: Emanuel De Martonne, Jules Sion, Albert Demangeon y Jean Brunhes. En Alemania, el abanderado de la geografía regional fue Alfred Hettner, en tanto, en Estados Unidos lo fue su alumno Richard Hartshorne.

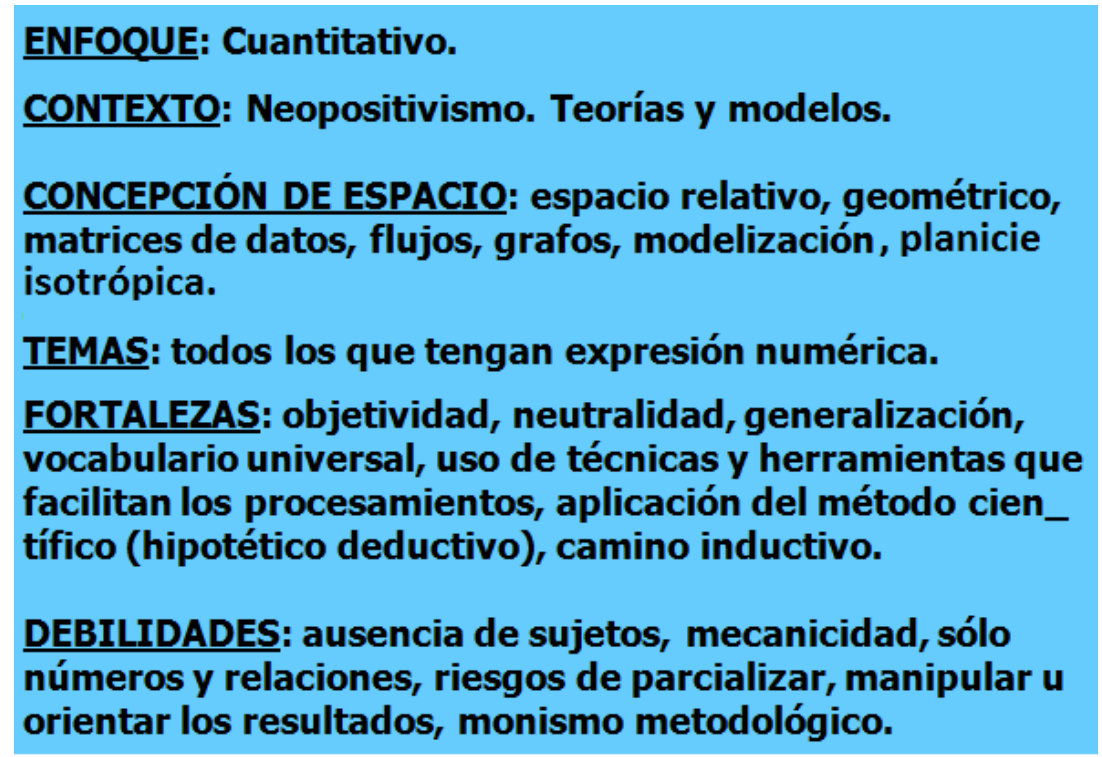

Época de surgimiento, áreas de difusión inicial y representantes destacados: surgió a fines en los años ' 40 y ganó trascendencia en la década siguiente, ante la falta de respuestas de la geografía regional a los problemas surgidos tras la segunda guerra mundial. Se propagó con mayor intensidad en Estados Unidos, Reino Unido y Alemania y, posteriormente, lo hizo en otros países europeos, 
americanos y del Este asiático. Algunas de sus figuras en el ámbito geográfico han sido: William Bunge, Peter Haggett, Richard Chorley y Fred Schaefer.

\section{ENFOQUE: Sistémico.}

\section{CONTEXTO: Neopositivismo. Teoría General de Sistemas.}

CONCEPCIÓN DE ESPACIO: sistema geográfico (una totalidad que involucra a un conjunto de elementos en interacción que componen una estructura donde circulan los ingresos en un tiempo determinando, generando una respuesta, la que vuelve a alimentar al sistema, garantizando sus funciones dentro de un equilibrio dinámico. (Flujos, modelización).

TEMAS: todos los que admitan una dinámica sistémica (sobre todo los físicos o naturales, sin descartar los sociales).

FORTALEZAS: objetividad, neutralidad, generalización, deducción, vocabulario universal, modelización, esquematización.

DEBILIDADES: ausencia de componentes subjetivos, mecanicidad (frías esquematizaciones), sólo números y relaciones, algoritmos, riesgos de simplificación de la realidad.

Época de surgimiento, áreas de difusión inicial y representantes destacados: este enfoque fue ampliamente conocido tras la publicación del trabajo que, por varias décadas, vino desarrollando Ludwig von Bertalanffy que, finalmente, se publicara en 1969 con el título de Teoría General de Sistemas. Tuvo una amplia aceptación entre biólogos, informáticos e ingenieros y, en la geografía, cobró importancia en los años '80. Entre quienes brindaron aportes importantes a esta concepción se encuentran William Ross Ashby, Joel de Rosnay, Oscar Johansen y West Churchmann. Tuvo repercusión inicialmente en Estados Unidos, Canadá y en varios países de Europa Occidental. En Argentina se reconocen, entre otros, los trabajos de Ricardo Capitanelli y Eliseo Popolizio en la aplicación de esta teoría en la geografía.

\section{ENFOQUE: Geografía Ambiental.}

CONTEXTO: Neopositivismo. Evolucionismo.Teoría General de Sistemas. Otras teorías y modelos. CONCEPCIÓN DE ESPACIO: ambiente (conjunto de valores naturales, sociales y culturales existentes en un lugar y en un momento determinado, que influyen en la vida del ser humano y en las generaciones venideras. No se trata sólo del espacio en el que se desarrolla la vida, sino que también comprende seres vivos, agua, suelo, aire, objetos y las relaciones entre ellos, como elementos tan intangibles como la cultura.

TEMAS: todos los que involucren relaciones reales y potenciales entre los grupos humanos y sus entornos o medios.

FORTALEZAS: generalización, uso de teorías y modelos, de técnicas, herramientas y recursos de captura, registro y procesamiento de los datos, indicadores, trabajos de campo y pruebas de laboratorio.

DEBILIDADES: el logro de equilibrios entre las demandas sociales, las pautas culturales, los intereses económicos y políticos (racionalidad humana) y la preservación de los complejos naturales o ecosistémicos. Falta de desarrollo teórico desde la ciencia geográfica.

Publicado en formato digital: Dr. Dante Edin Cuadra. LOS ENFOQUES DE LA GEOGRAFÍA EN SU EVOLUCIÓN COMO CIENCIA. Revista Geográfica Digital. IGUNNE. Facultad de Humanidades. UNNE. Año 11. No 21. Enero - Junio 2014. ISSN 1668-5180 Resistencia, Chaco.

En: http://hum.unne.edu.ar/revistas/geoweb/default.htm 
Época de surgimiento, áreas de difusión inicial y representantes destacados: su aparición es lejana, podría remontarse a Estrabón y Ptolomeo, pero se la identifica con mayor claridad a partir del siglo XVIII y, sobre todo, en el XIX con las contribuciones de Humboldt, Ritter, Ratzel, Richthofen y Davis. En el siglo XX aportaron Vidal de La Blache, Brunhes y Sorre; también lo hicieron Barrows y Churchill Semple. Logró expandirse en Estados Unidos, Reino Unido, Francia, Alemania y numerosos países del mundo. En Argentina tuvo mayor expansión en los años '90, debido a la reforma constitucional que posibilitó cambios normativos, explotación intensiva de los recursos naturales (merced a la privatización o concesión de yacimientos y empresas estatales) e incorporación de los temas ambientales en las currículas educativas. Entre los geógrafos que aportaron a esta perspectiva en el país se encuentran Carlos Reboratti, Jorge Pickenhayn y Diana Durán.

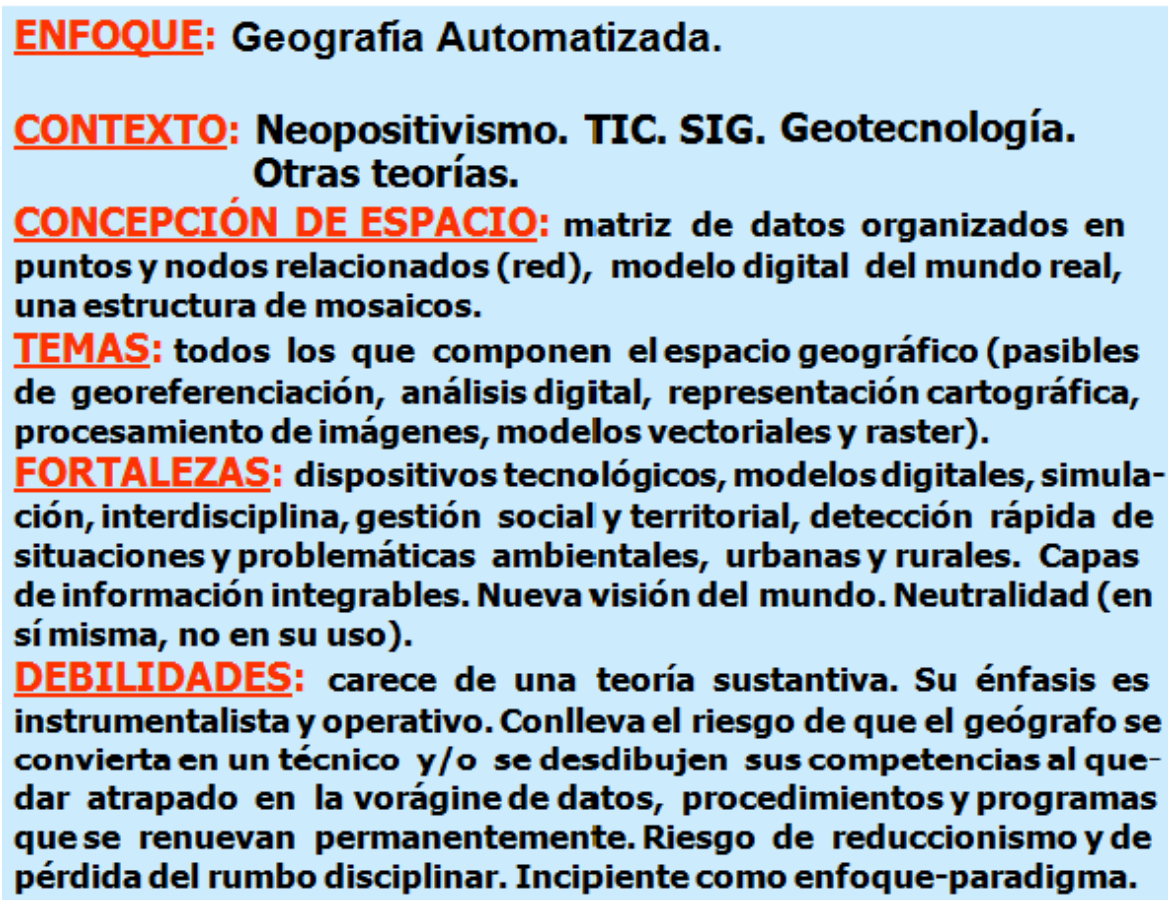

Época de surgimiento, áreas de difusión inicial y representantes destacados: esta perspectiva en geografía tomó fuerza a partir de los años '80, impulsada por los grandes avances en materia de tecnologías de la información y de la comunicación. Los debates continúan sobre la condición paradigmática de la geotecnología y la legitimidad de la geografía automatizada como enfoque geográfico. La concepción de "ciberespacio" como matriz electrónica de interconexión entre bancos de datos digitales a través de los sistemas computacionales conectados a la red mundial es, en cierta medida, admitir una nueva faceta de la espacialidad y, a la vez, un tema que produce crispaciones en algunos geógrafos, en tanto para otros, representa una perspectiva atractiva y desafiante.

En este trabajo, a diferencia de la postura de Buzai ya citada, se considera a la geografía automatizada como un enfoque geográfico, cuyo contexto paradigmático sería la filosofía positivista, en tanto la geotecnología oficiaría de nexo o interface entre ellos, junto a las teorías de la información y la comunicación, la teoría general de sistemas y una gran diversidad de teorías (por ejemplo, la del caos o de la decisión).

Entre los representantes puede citarse a Jerome Dobson, Jaishree Beedasy, Duncan Whyatt, Joaquín Bosque Sendra y, en Argentina, como ya se enunciara, son importantes las contribuciones de Gustavo Buzai. Lógicamente, los países con fuerte desarrollo tecnológico van a la vanguardia de las innovaciones a nivel de hardware y software, como ocurre con Estados Unidos, Japón, China, Canadá y estados de Europa centro-occidental y nórdica. 


\title{
ENFOQUE: Geog. de la Percepción y el Comportamiento CONTEXTO: Conductismo, (Positivismo)*. CONCEPCIÓN DE ESPACIO: espacio percibidoy sentido (subjetivo). Mapas mentales, imagen, conducta. Distan- cia psicológica y social. * Medir la imagen que la gente tiene de un espacio. \\ TEMAS: amplia difusión en Geografía Urbana. \\ FORTALEZAS: toma en cuenta al sujeto, sus sentimientos, preferencias y rechazos. Brinda elementos para la plani- ficación del espacio. Se despega de los condicionantes económicos.
}

\section{DEBILIDADES: gran despliegue de técnicas para llegar a resultados obvios, escasa difusión en muchos países, no se expandió a la diversidad de temas geográficos (falta de trascendencia fuera de lo urbano-ambiental).}

Época de surgimiento, áreas de difusión inicial y representantes destacados: se desarrolló en Estados Unidos en las décadas del '60 y '70 y se expandió en países como Inglaterra y Australia. En Argentina tuvo aplicación en algunas universidades y órganos estatales desde los años '80. Contribuyeron en su desarrollo teórico figuras como Kenneth Boulding, Peter Gould y Kevin Lynch.

\author{
ENFOQUE: Geografía Radical. \\ CONTEXTO: ideas de izquierda (Marx, Engels, Kropotkin y \\ trabajos neomarxistas. Materialismo histórico). \\ CONCEPCIÓN DE ESPACIO; espacio como producto de las rela- \\ ciones sociales (fuerza de trabajo, propiedad colectiva de los medios \\ de producción, distribución de los bienes sociales, clases sociales, \\ modelo económico, injusticia espacial).
}

TEMAS: problemáticas sociales (hambre, hacinamiento, violencia, pobreza, desigualdades, pueblos originarios, actores y tejido social).

FORTALEZAS: preocupación y compromiso social. Devela aspectos tradicionalmente ocultados por otras perspectivas (invisibilizados). Cuestiona los modelos injustos. Empatía por los excluidos o marginados del sistema.

DEBILIDADES: excesiva crítica y escaso sustento teórico-metodo_ lógico, la poca relevancia dada por Marx al espacio.

Época de surgimiento, áreas de difusión inicial y representantes destacados: el enfoque crítico radical logró emerger en la década del ' 60 en Estados Unidos, para luego, en los decenios siguientes, lograr abrirse paso en otros países como Francia y España y en diferentes puntos del globo, entre ellos Italia, Brasil y Argentina. Algunas de sus figuras relevantes son: Yves Lacoste, David Harvey, Horacio Capel, Milton Santos y Massimo Quaini. Se erigió como una postura antineopositivista al considerar que los postulados cuantitativos y sistémicos no sólo fracasan en aliviar la situación de los

Publicado en formato digital: Dr. Dante Edin Cuadra. LOS ENFOQUES DE LA GEOGRAFÍA EN SU EVOLUCIÓN COMO CIENCIA. Revista Geográfica Digital. IGUNNE. Facultad de Humanidades. UNNE. Año 11. $N^{0}$ 21. Enero - Junio 2014. ISSN 1668-5180 Resistencia, Chaco.

En: http://hum.unne.edu.ar/revistas/geoweb/default.htm 
excluidos de la sociedad, sino que la ocultan o la omiten. En contraposición, abogan por la geografía del compromiso social, entendiendo que los geógrafos deben inmiscuirse en los problemas e injusticias que se generan en la sociedad y orientar su tarea a romper con las desigualdades, las asimetrías y la exclusión.

\author{
ENFOQUE: Geografía Humanista. \\ CONTEXTO: amplio (Fenomenología, Existencialismo, Idealismo, \\ Marxismo, Socialismo, Cristianismo, neomarxismo). \\ CONCEPCIÓN DE ESPACIO: antropocéntrico, lugar (sub- \\ jetivo, vivencial, cargado de valores y sentimientos, iden- \\ tidad, arraigo, idiosincrasia, representaciones). Topofilia. \\ TEMAS: sociales, muchas veces acotados a lo local, \\ barrial, urbano, a problemáticas específicas: convivencia, \\ intolerancia, problemas identitarios, marginación, trabajo \\ infantil, discriminación, etc.
}

FORTALEZAS: realza la condición humana, rescata temas y problemas que, por su extensión puntual o local o por la misma debilidad de los afectados, son invisibilizados socialmente.

\title{
DEBILIDADES: escaso desarrollo teórico-metodológico. Amplitud
}

discursiva y carencia de praxis y resultados.

Época de surgimiento, áreas de difusión inicial y representantes destacados: la perspectiva humanista tuvo su aparición en el escenario geográfico en la década de 1970, gracias a los aportes e David Ley, Marwyn Samuels, Richard Peet, Edward Relph, Yi-Fu Tuan y Anne Buttimer. Fue considerado un enfoque crítico, pero más flexible y abierto que el radical marxista y se propagó inicialmente entre los geógrafos de Estados Unidos y del Reino Unido, pero con el transcurso del tiempo tuvo acogida favorable en muchos países del mundo en la medida en que el humanismo lograba poner al hombre en un lugar central, al tiempo que el capitalismo y la globalización se empeñaban por lo contrario.

\section{ENFOQUE: Geografía Cultural (años '20 a '80 del S. XX) \\ CONTEXTO: estudios históricos, regionales, paisajísticos, etnográficos, antropológicos.}

CONCEPCIÓN DE ESPACIO: paisaje que expone las huellas de la cultura a través del tiempo; formas adquiridas por el territorio por incidencia de las pautas culturales; espacio concreto, materialidades.

TEMAS: paisajes y poblaciones rurales.

FORTALEZAS: contempla el papel de la cultura en el espacio y no sólo los factores económicos o políticos. Es antideterminista, si bien admite influencias del medio sobre las pautas culturales. Asume el papel del proceso histórico en la producción de espacio.

DEBILIDADES: no ha alcanzado una fuerte difusión fuera de Estados Unidos, Francia o España. El objeto de estudio es un poco difuso, en tanto el desarrollo teórico-metodológico es restringido.

Publicado en formato digital: Dr. Dante Edin Cuadra. LOS ENFOQUES DE LA GEOGRAFÍA EN SU EVOLUCIÓN COMO CIENCIA. Revista Geográfica Digital. IGUNNE. Facultad de Humanidades. UNNE. Año 11. $N^{0}$ 21. Enero - Junio 2014. ISSN 1668-5180 Resistencia, Chaco.

En: http://hum.unne.edu.ar/revistas/geoweb/default.htm 
Época de surgimiento, áreas de difusión inicial y representantes destacados: la geografía cultural fue desarrollada en los Estados Unidos por Carl Sauer, convirtiéndose en el líder de la escuela de Berkeley, donde se impulsó la idea de la morfología del paisaje. Sus contribuciones a la geografía histórica también han sido de gran relevancia. En Francia, los aportes de Max Sorre y de Paul Claval a la geografía cultural han gozado del reconocimiento internacional y, del mismo modo, los trabajos de Schultze en Alemania, de Hans Bobek en Austria y de Renato Biasutti en Italia.

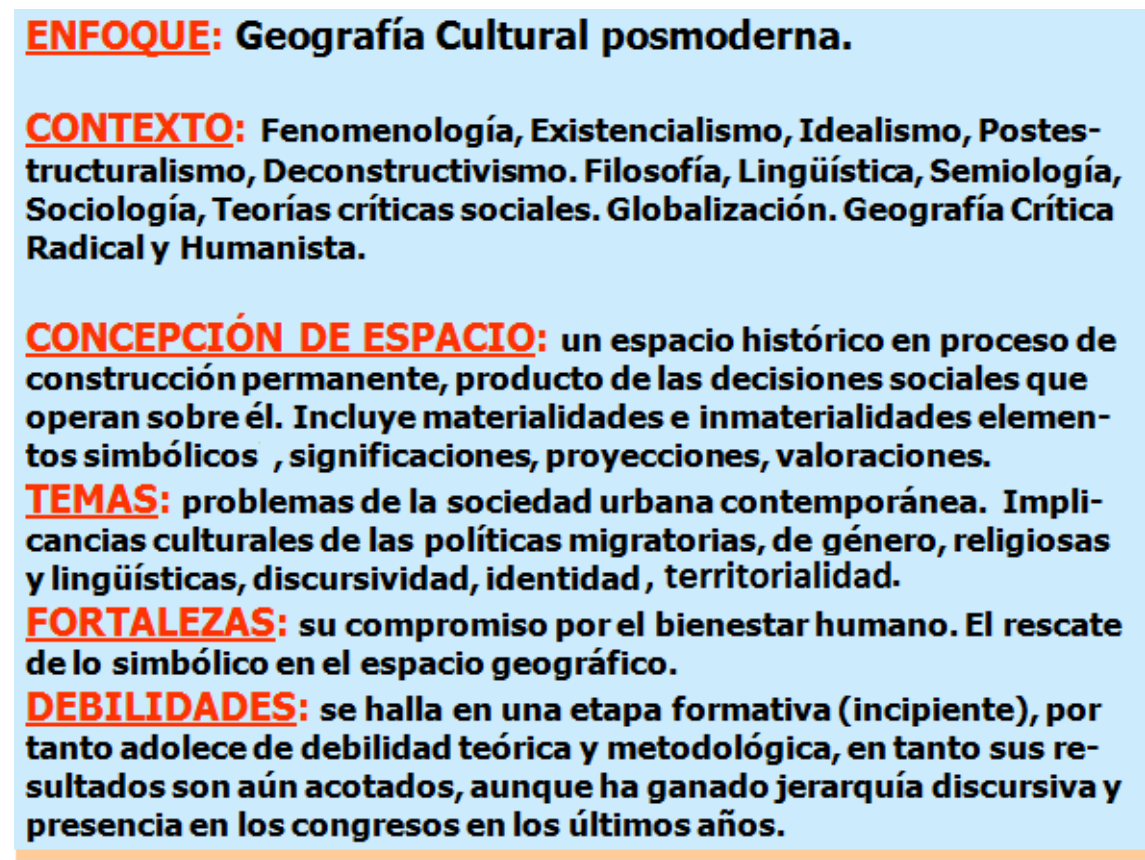

Época de surgimiento, áreas de difusión inicial y representantes destacados: la geografía cultural se ha innovado y resignificado desde los '80, tras el giro cultural vivido por la sociedad tardocapitalista y globalizada. Estados Unidos, Reino Unido, Francia y numerosos países, entre los que se hallan Brasil y Argentina, vienen haciendo aportes geográficos ante la incidencia social y espacial de los cambios culturales acelerados por la vorágine tecnológica de los últimos treinta años. Todo ha cambiado en nuestro mundo: las formas de comunicarnos, las discursividades, las herramientas de análisis, las concepciones de tiempo y espacio, los desplazamientos humanos, las relaciones económicas y políticas entre los estados, la aparición de nuevos problemas ambientales y sociales, la instalación de nuevas y complejas redes que potencian a unos y excluyen a otros y, por tanto, la gestación de nuevas territorialidades. Se trata de "...un mundo que se mueve con distintas velocidades y que articula múltiples escalas” (Blanco, J., 2009), donde el tiempo y el espacio parecieran plegables.

Lo que se da en llamar geografía cultural posmoderna, no tiene fronteras claras con la geografía humanista e, incluso, con la geografía radical, por lo que habrá que ver si se trata de un nuevo enfoque (a modo de resurgimiento de la geografía cultural saueriana-clavaliana) o un movimiento integrador que posiciona en el mismo pedestal o perspectiva a varios enfoques que tienen en su foco de atención al hombre y que, en consecuencia, tienen como brújula la igualdad social, la justicia espacial, los componentes simbólicos del espacio, entendiendo al territorio como un espacio de relaciones (sociales, políticas, culturales, económicas, tecnológicas, locales, globales). Pensadores y filósofos como Heidegger, Husserl, Foucault, Lyotard y Derrida, entre otros, han brindado ideas y conceptos interesantes a la hora de analizar las nuevas espacialidades. Geógrafos eminentes como David Harvey, Dennis Cosgrove, Regério Haesbaert, Edward Soja y Doreen Massey han aportado cierta claridad al rumbo que deberá tomar la disciplina, aunque todavía resta recorrer un largo camino para entender qué es exactamente y hacia dónde se encamina la posmodernidad, una etapa llena de sorpresas y desafíos para las generaciones de geógrafos que vivimos este sorprendente tramo de la historia.

Publicado en formato digital: Dr. Dante Edin Cuadra. LOS ENFOQUES DE LA GEOGRAFÍA EN SU EVOLUCIÓN COMO CIENCIA. Revista Geográfica Digital. IGUNNE. Facultad de Humanidades. UNNE. Año 11. No 21. Enero - Junio 2014. ISSN 1668-5180 Resistencia, Chaco.

En: http://hum.unne.edu.ar/revistas/geoweb/default.htm 
Al decir de Massey, "El espacio es producto de interrelaciones, redes de relaciones, lugar de encuentro, articulaciones múltiples, experiencias y entendimientos sociales". (Massey, D., 2001). En este contexto, no pueden faltar las miradas, los trabajos y los aportes que los geógrafos sabemos hacer y que tan necesarios resultan en un mundo cada vez más diverso, dinámico y desconcertante que nos obliga a reposicionarnos, a desprendernos de ciertos conceptos estáticos de nuestra formación e incorporar al trabajo cotidiano una amplia gama de situaciones, procesos y realidades novedosos que se generan a nuestro alrededor. Más que nunca, entonces, se hace imprescindible que el geógrafo desarrolle "...un pensamiento complejo, reflexivo, multicausal”. (Fernández, Caso, M. V., 2009)

\section{Bibliografía consultada}

Augé, Marc (2000). Los no lugares. Espacios del anonimato. Una antropología de la sobremodernidad. Gedisa Editorial. $5^{\circ}$ edición. Barcelona, España.

Blanco, Jorge (2009). Espacio y territorio: elementos teórico-conceptualesx implicados en el análisis geográfico. En: Fernández Caso, María y Gurecich, Raquel (Coordinadoras). Geografía. Nuevos temas, nuevas preguntas. Un temario para su enseñanza. Ed. Biblos. 37-64. Buenos Aires, Argentina.

Buzai, Gustavo (1998). Impacto de la Geotecnología en el desarrollo teórico-metodológico de la ciencia geográfica. Hacia un nuevo paradigma en los albores del siglo XXI. Tesis doctoral. Fac. de Filosofía y Letras. Universidad Nacional de Cuyo. Mendoza, Argentina.

Buzai, Gustavo (1999). Geografía Global. El Paradigma Geotecnolágico y el Espacio Interdisciplinario en la Interpretación del Mundo del Siglo XXI. Lugar Editorial, $1^{\circ}$ Edición. Buenos Aires, Argentina.

Buzai, Gustavo (2011). Geografía y Sistemas de Información Geográfica. Revista Geográfica de América Central. Número Especial. Editorial de la Universidad Nacional de Costa Rica. $I^{\circ}$ Semestre. San José, Costa Rica.

Capel, Horacio (1976). Filosofía y Ciencia en la Geografía Contemporánea. $2^{\circ}$ edición. Ed. Barcanova. Barcelona, España.

Christofoletti, Antonio (1983). Definicao e Objeto de Geografía. Revista Geográfica. Vol. 8. Sâo Paulo, Brasil.

Claval, Paul (1999). Geografía Cultural. Editorial de la Universidad Nacional de Buenos Aires (EUDEBA). Buenos Aires, Argentina.

Daus, Federico (1961). ¿Qué es la Geografía?. Ed. Columba. Buenos Aires, Argentina.

Durán, Diana (1972). El método de la Geografía. Cuestiones epistemológicas. Ed. Oikos. Buenos Aires, Argentina.

Estebanez, José (1992). Tendencias y problemática actual de la Geografía. Ed. Cincel. Madrid, España.

Fernández Caso, María y Gurecich, Raquel -Coordinadoras- (2009). Geografía. Nuevos temas, nuevas preguntas. Un temario para su enseñanza. Ed. Biblos. Buenos Aires, Argentina.

García Ballesteros, Aurora (1986). Teoría y Práctica de la Geografía. Alambra Universidad. Madrid, España.

Publicado en formato digital: Dr. Dante Edin Cuadra. LOS ENFOQUES DE LA GEOGRAFíA EN SU EVOLUCIÓN COMO CIENCIA. Revista Geográfica Digital. IGUNNE. Facultad de Humanidades. UNNE. Año 11. No 21. Enero - Junio 2014. ISSN 1668-5180 Resistencia, Chaco.

En: http://hum.unne.edu.ar/revistas/geoweb/default.htm 
Gómez Mendoza, Josefina et al (1982). El pensamiento geográfico. Ed. Alianza Universidad. Madrid, España.

Harvey, David (1983). Teoría, leyes y modelos en Geografía. Ed. Alianza Universidad. Madrid, España.

Harvey, David (1998). La condición de la posmodernidad. Amorrortu Editores. Buenos Aires, Argentina.

Massey, Doreen (2001). Space, Place, and Gender. Minneapolis: University of Minnesota Press. Minnestota, USA.

Massey, Doreen (2004). Lugar, identidad y geografías de la responsabilidad en un mundo en proceso de globalización. Treballs de la Societat Catalana de Geografia. № 57. 77-84. Barcelona, España.

Moraes, Antonio et al (1984). La Geografía Crítica. La valorización del espacio. Ed. Hucitec. Sâo Paulo, Brasil.

Oropeza, Mónica y Díaz, Norelis (2007). La geotecnología y su inserción en el pensamiento geográfico. Terra. Vol. 23, № 34. Caracas, Venezuela.

Ortega Cantero, Nicolás (1998). Geografía y Cultura. Alianza Universidad. Madrid, España.

Ortega Valcárcel, José (2000). Los horizontes de la Geografía. Ed. Ariel S.A. Barcelona, España.

Ortega Valcárcel, José (2002). Teoría de la Geografía. Ariel Editorial. Barcelona, España.

Ostuni, Josefina (1992). Introducción a la Geografía. Colección Geográfica. Ed. CEYNE. San Juan, Argentina.

Peña, Orlando y Sanguin, Ander (1984). El mundo de los geógrafos. Ed. Oikos-Tau. Barcelona, España.

Pickenhayn, Jorge (1994). Epistemología y Geografía. Ed. Plus Ultra. Buenos Aires, Argentina.

Popolizio, Eliseo (1987). El enfoque sistémico en la enseñanza de la Geografía. Boletín GAEA No 106. Buenos Aires, Argentina.

Randle, Patricio (1977). Teoría de la Geografía. Tomos I y II. Ed. Oikos. Buenos Aires, Argentina.

Rey Balmaceda, Raúl (1972). Geografía Regional. Teoría y aplicación. Ed. Estrada. Buenos Aires, Argentina.

Santarelli de Serer, Silvia y CAMPOS, Marta (2002). Corrientes epistemológicas, metodología y prácticas en Geografía. Propuestas de estudio en el espacio local. Universidad Nacional del Sur. Bahía Blanca, Argentina.

Santos, Milton (1990). Por una geografía nueva. Ed. Espasa-Calpe. Madrid, España.

Santos, Milton (1996). Metamorfosis del espacio habitado. Ed. Hucitec. Sâo Paulo, Brasil.

Santos, Milton (2000). La naturaleza del espacio. Ed. Ariel. Barcelona, España.

Publicado en formato digital: Dr. Dante Edin Cuadra. LOS ENFOQUES DE LA GEOGRAFíA EN SU EVOLUCIÓN COMO CIENCIA. Revista Geográfica Digital. IGUNNE. Facultad de Humanidades. UNNE. Año 11. № 21. Enero - Junio 2014. ISSN 1668-5180 Resistencia, Chaco.

En: http://hum.unne.edu.ar/revistas/geoweb/default.htm 
Schaefer, Fred (1953). Excepcionalismo en Geografía; un Análisis Metodológico. Anales de la Asociación Americana de Geógrafos, Vol. № 43. Universidad de Barcelona. Barcelona, España.

Silva, Miguel A. (2000). La Geografía entre el discurso y la realidad. Reflexiones en torno a un tema central. Revista Huellas $N^{\circ}$ 8. Universidad Nacional de La Pampa. Santa Rosa, Argentina.

Silva, Miguel A. (2008). La Geografía Cultural. Rasgos centrales en su constitución y procedimientos. Revista Huellas № 12. Universidad Nacional de La Pampa. Santa Rosa, Argentina.

Soja, Edward (2010). Seeking Spatial Justice. University of Minnesota Press Minneapolis, Estados Unidos.

Tuan, Yi-Fu (2007). Topofilia. Ed. Melusina S.L. España.

Unwin, Tim (1995). El lugar de la Geografía. Ed. Cátedra. Madrid, España.

Vila Valentí, Juan (1983). Introducción al estudio teórico de la Geografía. Ed. Ariel. Barcelona, España.

Publicado en formato digital: Dr. Dante Edin Cuadra. LOS ENFOQUES DE LA GEOGRAFíA EN SU EVOLUCIÓN COMO CIENCIA. Revista Geográfica Digital. IGUNNE. Facultad de Humanidades. UNNE. Año 11. No 21. Enero - Junio 2014. ISSN 1668-5180 Resistencia, Chaco.

En: http://hum.unne.edu.ar/revistas/geoweb/default.htm 